\title{
MINIMUM-DETECTABLE ACTIVITY OF BETA-PARTICLE EMITTERS BY SPECTRUM ANALYSIS*
}

\author{
PHILLIP PLATO \\ Dept. of Environmental and Industrial Health, School of Public Health, \\ The University of Michigan, Ann Arbor, Michigan 48104, U.S.A. \\ and \\ WILLIAM L. OLLER \\ National Center for Toxicological Research, Jefferson, Arkansas 72079, U.S.A.
}

Received 27 December 1974

\begin{abstract}
Minimum-detectable activities (MDAs) for ${ }^{3} \mathrm{H},{ }^{14} \mathrm{C}$, and ${ }^{32} \mathrm{P}$ were determined experimentally by the method of beta-particle spectrum analysis and compared to corresponding theoretically possible MDAs using the integrated count rate for each radionuclide. The lowest MDAs determined experimentally for ${ }^{3} \mathbf{H}$, ${ }^{14} \mathrm{C}$, and ${ }^{32} \mathrm{P}$ were $5.5,3.5$, and 2.5 picocuries, respectively.
\end{abstract}

\section{Introduction}

Isotopic analysis of samples of unknown composition for gamma-ray-emitting radionuclides can usually be conducted without difficulty provided that the gammaray abundance is sufficient and the gamma-ray photopeaks can be resolved by a scintillation or solid-state system. However, the analysis of complex mixtures of beta-particle-emitting radionuclides generally involves chemical separations to isolate all isotopes of a given element present in a sample followed by analyses of each fraction of the sample for total beta-particle activity.

A new method was developed to produce betaparticle spectra ${ }^{1}$ ). The spectra are produced by coupling a liquid scintillation analyzer (LSA) to a multichannel pulse-height analyzer (MCA). The LSA has three independent single-channel analyzers. The linear amplifier of each single-channel analyzer is adjusted to provide optimum gain for a given energy range (e.g., 1.5 to $25 \mathrm{keV}, 25$ to $256 \mathrm{keV}$, and 256 to $2560 \mathrm{keV}$ ). The discriminated signals from each singlechannel analyzer are routed to a separate 256-channel portion of the MCAs memory. Thus, a single betaparticle spectrum is produced using 768 channels of the MCA with each third of the spectrum having a different energy scale (e.g., $0.1,1$, and $10 \mathrm{keV}$ per channel).

The cost of the ancillary equipment to couple an LSA to an MCA is approximately $5 \%$ of the combined

* This work was performed at the School of Public Health, The University of Michigan, Ann Arbor, Michigan 48104, U.S.A
MDA values were determined for these three radionuclides individually, and for ${ }^{3} \mathrm{H}$ in the presence of ${ }^{14} \mathrm{C}$ and ${ }^{32} \mathrm{P}$ to demonstrate the influence of other radionuclides on the MDA of a given radionuclide. MDA values were also determined for the three radionuclides as a function of sample counting time.

cost of the two instruments. The two instruments are not altered by the procedure that combines them into one scintillation system. The instruments can operate independently of one another by disconnection of three analog signal cables from the liquid scintillation analyzer

Among the beta-emitting nuclides released to the environment in the routine operation of nuclear facilities such as nuclear power reactors ${ }^{2}$ ) are ${ }^{3} \mathrm{H},{ }^{14} \mathrm{C}$, and ${ }^{32} \mathrm{P}$. These three radionuclides were used in the development of this method of beta-particle spectrum analysis for this reason and because:

a) The respective energies of ${ }^{3} \mathrm{H}\left(E_{\max }: 18.6 \mathrm{keV}\right)$, ${ }^{14} \mathrm{C}\left(E_{\max }: 156 \mathrm{keV}\right)$, and ${ }^{32} \mathrm{P}\left(E_{\max }: 1710 \mathrm{keV}\right)$ afford easy separation for quantitative analysis by liquid scintillation techniques.

b) The energy range, 0 to $1710 \mathrm{keV}$, is representative

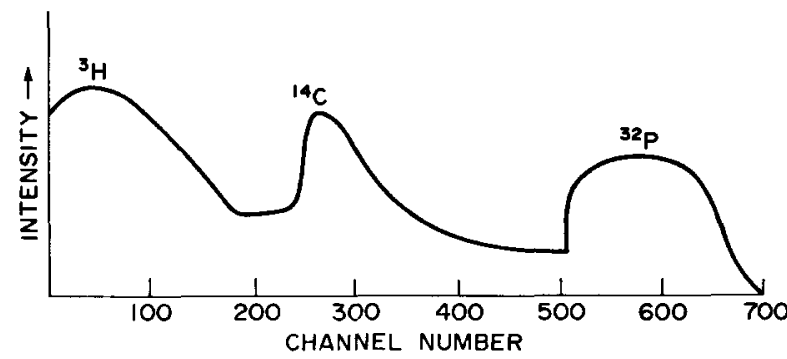

Fig. 1. A composite beta-particle spectrum from a sample that contained ${ }^{3} \mathrm{H},{ }^{14} \mathrm{C}$, and ${ }^{32} \mathrm{P}$ recorded by this method of betaparticle spectrum analysis (Oller and Plato, 1972). 
of the beta-particle emitters that may be present in the environs of a nuclear facility.

Therefore, these radionuclides, which have maximum kinetic energies that differ by a factor of ten, served to test the proposed method of beta-particle spectrum analysis. Fig. 1 shows a typical beta-particle spectrum recorded by this method from a single sample that contained ${ }^{3} \mathrm{H},{ }^{14} \mathrm{C}$, and ${ }^{32} \mathrm{P}$.

Previous work ${ }^{1}$ ) showed beta-particle spectrum analysis to be a feasible method to analyze mixtures of ${ }^{3} \mathrm{H},{ }^{14} \mathrm{C}$, and ${ }^{32} \mathrm{P}$. However, no attempt was made during the early feasibility study to determine the minimum-detectable activity (MDA) of these radionuclides by beta-particle spectrum analysis. Therefore, three objectives defined for the study reported in this paper are:

1) To determine the MDAs for ${ }^{3} \mathrm{H},{ }^{14} \mathrm{C}$, and ${ }^{32} \mathrm{P}$ in the absence of other radionuclides.

2) To determine the influence of other radionuclides on the MDA of a given radionuclide.

3) To determine the relationship between counting time and the MDAs of ${ }^{3} \mathrm{H},{ }^{14} \mathrm{C}$, and ${ }^{32} \mathrm{P}$.

\section{Method of spectrum analysis}

A weighted-least-squares method of spectrum analysis that was originally developed to analyze gamma-ray spectra, was modified to analyze betaparticle spectra and programmed for an IBM 360 computer $^{3}$ ). The computer program has two requirements for sample analysis: each radionuclide that is present in a sample must be specified in the analysis request, and each radionuclide must have a spectrum in the reference library. A request for sample analysis may specify more (but never less) radionuclides than the sample contains. The set of reference spectra is called the reference library. Each reference spectrum is a linear array of numbers with units of $\mathrm{cpm} / \mathrm{channel}$. The computer program constructs a single spectrum from specified radionuclides in the reference library to match a sample spectrum, minimizing the sum of the squares of the differences between the two spectra.

The activity of each reference source used to produce a spectrum in the reference library must be known. The accuracy of the predicted amount cannot be greater than the accuracy of the reference source.

Among the parameters listed in the read-out format that the analyst must evaluate are the chi-square value for goodness of fit, the degrees of freedom associated with the chi-square value, and the standard deviation of the observed amount of each radionuclide. The read-out format also provides the analyst with two graphic displays of the sample spectrum: the sample spectrum with the least-squares fit of the reference spectra, and the sample spectrum that remains after the fitted reference spectra have been subtracted.

These data assist the analyst and make data processing faster and easier than manual techniques. The two graphic displays and the information contained in the read-out format will indicate one of the following conditions:

a) The observed activity appears reasonable and should be accepted.

b) The sample activity is below the minimum-detectable activity.

c) The sample is quenched and needs quench correction.

d) The sample contains a spectrum that was not provided in the reference library.

e) The sample contains too many radionuclides, and a chemical separation is required.

\section{Results}

The sensitivity of liquid scintillation analyzers to detect weak beta-particle emitters, especially ${ }^{3} \mathrm{H}$ and ${ }^{14} \mathrm{C}$, has contributed to the success of the instrument. Instrument sensitivity is the minimum amount of radioactivity a sample must have for the instrument to respond, and is reported as the MDA for a given radionuclide.

The method normally used to count a radionuclide with a liquid scintillation analyzer utilizes an integrated count rate of all beta particles emitted by the radionuclide. The theoretical integrated count rate that can be detected above background is calculated ${ }^{4}$ ) by the following relationship:

$$
\tau=\left(r_{1}-r_{2}\right) /\left[\frac{r_{1}}{t_{1}}+\frac{r_{2}}{t_{2}}\right]^{\frac{1}{2}},
$$

where:

$r_{1}$ is the integrated count rate of radionuclide plus background (cpm);

$r_{2}$ is the integrated count rate of background (cpm); $t_{1}$ is the counting time of radionuclide plus background (min);

$t_{2}$ is the counting time of background ( $\mathrm{min}$ );

$\tau$ is the relative error.

The theoretical MDA in units of picocuries is then calculated for a given counting efficiency $(\varepsilon)$ by the relationship:

$$
M D A=\frac{r_{1}-r_{2}}{\varepsilon 2.22 \mathrm{dpm} / \mathrm{pCi}} .
$$


Theoretical MDAs, shown in fig. 2, were calculated for ${ }^{3} \mathrm{H},{ }^{14} \mathrm{C}$, and ${ }^{32} \mathrm{P}$, based on the assumption that integrated count rates were used for each radionuclide rather than beta-particle spectra. The integrated background count rate was $25 \mathrm{cpm}$ for ${ }^{3} \mathrm{H}, 21 \mathrm{cpm}$ for ${ }^{14} \mathrm{C}$, and $19 \mathrm{cpm}$ for ${ }^{32} \mathrm{P}$. The counting efficiency was $40 \%$ for ${ }^{3} \mathrm{H}, 60 \%$ for ${ }^{14} \mathrm{C}$, and $90 \%$ for ${ }^{32} \mathrm{P}$. A $95 \%$ confidence level $(\tau=1.96)$ was used, and the background counting time was assumed to be 50000 seconds.

The experimental method used to determine an MDA by beta-particle spectrum analysis involved analysis of samples that contained less and less activity until the observed activity (determined with the least-squares

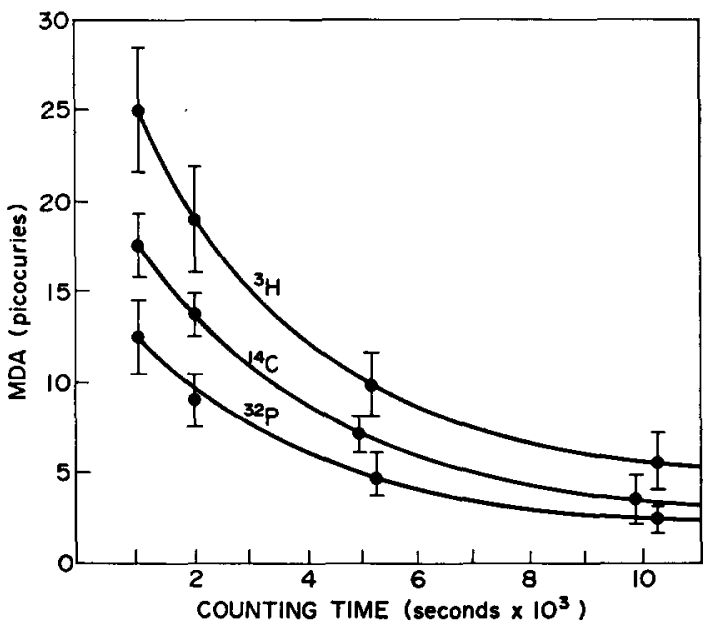

Fig. 2. The theoretical change in MDA of ${ }^{3} \mathrm{H},{ }^{14} \mathrm{C}$, and ${ }^{32} \mathrm{P}$ determined by eqs. (1) and (2) at the $95 \%$ confidence level.

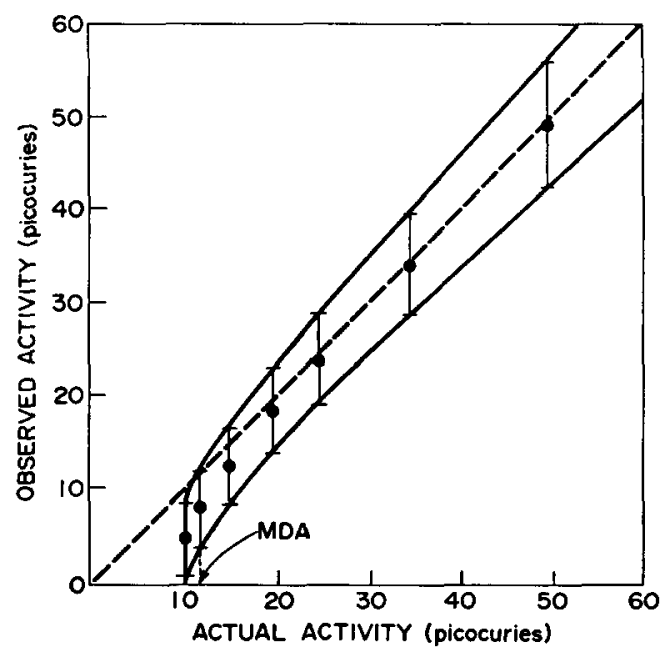

Fig. 3. Method used to determine the MDA of a radionuclide by beta-particle spectrum analysis. Actual activities are plotted against observed activities at the $95 \%$ confidence level. A twosigma error limit curve is constructed to calculate the MDA. computer program) was below detection limits. For a given set of counting conditions, the observed activities obtained from the least-squares computer program and the associated $95 \%$ confidence limits were plotted against the actual activities present. A straight line with a $45^{\circ}$ slope was plotted to show the ideal condition where observed equals actual. Smooth curves were drawn through the upper and the lower values of the $95 \%$ confidence limits associated with the observed activities. The intercept of the upper error limit curve with the ideal straight line determined the MDA. Fig. 3 shows a representation of this method used to determine an MDA by beta-particle spectrum analysis.

Fig. 4 shows the decrease in the experimental MDAs for ${ }^{3} \mathrm{H},{ }^{14} \mathrm{C}$, and ${ }^{32} \mathrm{P}$ as the sample counting time increases, when the least-squares method is used to analyze single-radionuclide beta-particle spectra at the $95 \%$ confidence level. Background counting time was 50000 seconds, and no detectable quench was present in the Aquasol ${ }^{\mathrm{TM}}$ cocktail solution. The experimentally determined curves in fig. 4 have approximately the same shapes as the theoretically calculated curves in fig. 2. Fig. 4 can be used to determine economical use of instrument counting time and/or to predict the MDA of a radionuclide for a specified counting time by the beta-particle spectrum-analysis method.

Table 1 shows the experimentally determined MDAs for the counting conditions specified (from fig. 4) and the corresponding theoretical MDAs (from fig. 2). The experimental MDAs are larger than the theoretical MDAs by a factor of between 5 and 13. Beta-particle spectrum analysis requires that the detected count rate

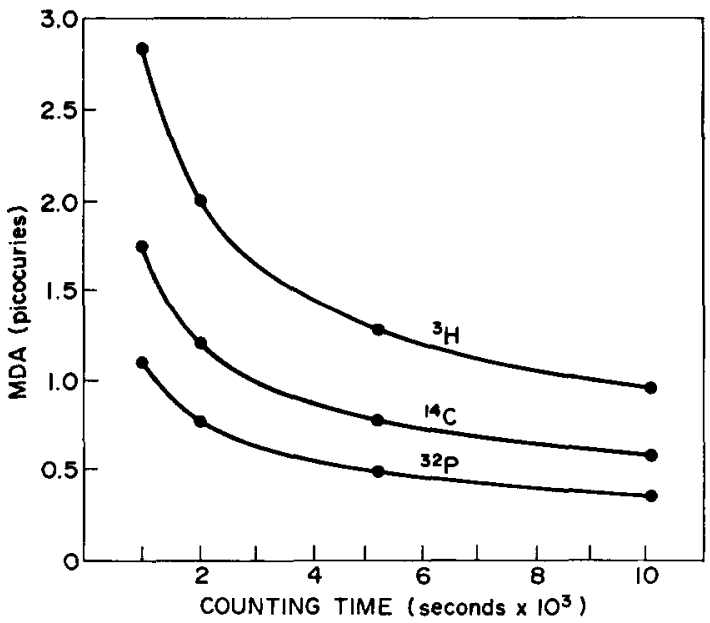

Fig. 4. The actual change in MDA of ${ }^{3} \mathrm{H},{ }^{14} \mathrm{C}$, and ${ }^{32} \mathrm{P}$ determined by beta-particle spectrum analysis at the $95 \%$ confidence level. 
TABLE 1

Comparison of MDAs, in units of picocuries, determined experimentally with the theoretical values calculated from eqs. (1) and (2). The $95 \%$ confidence level was used for the experimental measurements and the theoretical calculations. A background counting time of 50000 seconds was used.

\begin{tabular}{|c|c|c|c|c|}
\hline \multirow[t]{2}{*}{ Radionuclide } & \multicolumn{4}{|c|}{ Sample counting time (seconds) } \\
\hline & 1000 & 2000 & 5000 & 10000 \\
\hline${ }^{3} \mathrm{H}-$ experimental & $26.5 \pm 3.5$ & $19.0 \pm 2.8$ & $10.0 \pm 1.9$ & $5.5 \pm 1.5$ \\
\hline${ }^{3} \mathrm{H}-$ theoretical & 2.9 & 2.0 & 1.3 & 1.0 \\
\hline${ }^{14} \mathrm{C}$ - experimental & $17.5 \pm 2.9$ & $13.5 \pm 2.3$ & $7.0 \pm 1.3$ & $3.5 \pm 1.3$ \\
\hline${ }^{14} \mathrm{C}$ - theoretical & 1.8 & 1.2 & 0.8 & 0.6 \\
\hline $32 \mathrm{P}$ - experimental & $14.3 \pm 2.1$ & $9.0 \pm 1.6$ & $5.0 \pm 1.4$ & $2.5 \pm 0.9$ \\
\hline $32 \mathrm{P}$ - theoretical & 1.1 & 0.8 & 0.5 & 0.4 \\
\hline
\end{tabular}

be distributed over a large number of channels; 256 channels were used to record each of the radionuclides shown in fig. 1 . This distribution results in poor counting statistics for each channel at very low count rates. Additional errors result from the attempt to fit the library reference spectra to a sample spectrum by the weighted-least-squares method.

The disadvantage of the relatively high MDAs with beta-particle spectrum analysis must be weighed against the advantage over conventional liquid scintillation counting of being able to observe a beta-particle spectrum produced by a sample. If the identities of the radionuclides present in a sample are known, and if no more than three radionuclides are present (one or two is preferred), then conventional liquid scintillation techniques are sufficient. However, if the sample contains radionuclides that are unknown qualitatively as well as quantitatively, then beta-particle spectrum analysis may be a valuable analytical procedure.

An MDA is generally determined in the absence of other radionuclides. If more than one radionuclide is present in a sample, those that decay with highenergy beta particles will interfere with the ability of any technique to detect radionuclides that decay with low-energy beta particles. The MDA for the radionuclides in question increases as the activities of interfering radionuclides increase.

Eqs. (1) and (2) were used to calculate the theoretical MDA of ${ }^{3} \mathrm{H}$ in the presence of various activities of ${ }^{14} \mathrm{C}$ and ${ }^{32} \mathrm{P}$ to demonstrate the effect of high-energy betaparticle emitters on the detection limit of a low-energy beta-particle emitter. The fractions of the ${ }^{14} \mathrm{C}$ and ${ }^{32} \mathrm{P}$ beta-particle spectra that interfere with a ${ }^{3} \mathrm{H}$ spectrum (see fig. 1) were found to be $32 \%$ and $2.2 \%$, respectively. Thus, a given activity of ${ }^{14} \mathrm{C}$ or ${ }^{32} \mathrm{P}$ will contribute a proportional count rate to the $25 \mathrm{cpm}$ integrated background count rate already present in the ${ }^{3} \mathrm{H}$ portion of the beta-particle spectrum.

Curves I and II in fig. 5 show the theoretical increase in the MDA of ${ }^{3} \mathrm{H}$ in the presence of increased activities of ${ }^{14} \mathrm{C}$ and ${ }^{32} \mathrm{P}$. A $95 \%$ confidence level $(\tau=1.96)$ was used, and the background and sample counting times were assumed to be 50000 seconds and 10000 seconds, respectively. Since the fraction of the ${ }^{32} \mathrm{P}$ spectrum that interferes with the ${ }^{3} \mathrm{H}$ spectrum is less than the interfering fraction of the ${ }^{14} \mathrm{C}$ spectrum, the influence of ${ }^{32} \mathrm{P}$ on the MDA of ${ }^{3} \mathrm{H}$ is less than the influence of ${ }^{14} \mathrm{C}$.

Curves III and IV in fig. 5 show the increase in the MDA of ${ }^{3} \mathrm{H}$ determined experimentally by the addition of increased activities of ${ }^{14} \mathrm{C}$ and ${ }^{32} \mathrm{P}$ in a sample. The weighted-least-squares method was used to analyze each spectrum at the $95 \%$ confidence level. The background and sample counting times were 50000 seconds and 10000 seconds, respectively.

The experimentally produced curves (III and IV) in fig. 5 have approximately the same shapes as the theoretical curves (I and II). However, as was observed when the sample counting time was the only variable (figs. 2 and 4), the experimentally determined MDAs are between 5 and 13 times larger than the theoretical MDAs.

To demonstrate the use of fig. 5, assume a sample containing ${ }^{3} \mathrm{H}$ and ${ }^{14} \mathrm{C}$ was analyzed by beta-particle spectrum analysis. If the results of the analysis showed that the sample contained $10000 \mathrm{pCi}$ of ${ }^{14} \mathrm{C}$ and no detectable ${ }^{3} \mathrm{H}$, it would be incorrect to report the ${ }^{3} \mathrm{H}$

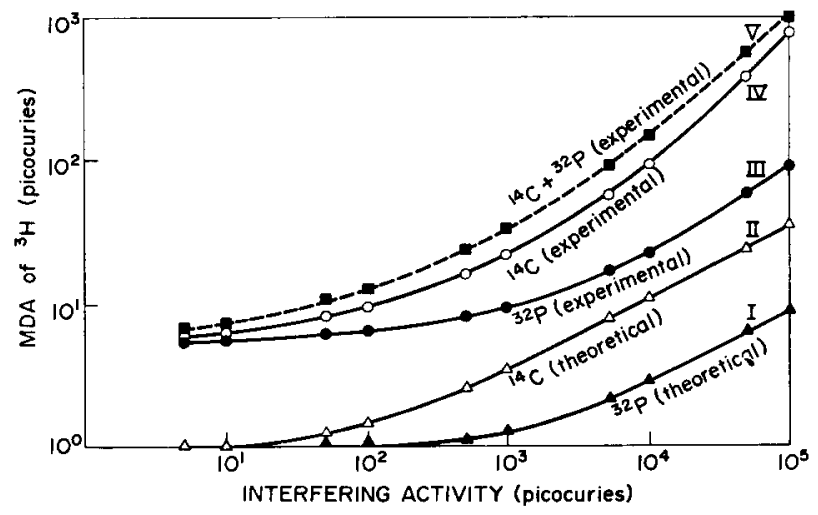

Fig. 5. Change in MDA of ${ }^{3} \mathrm{H}$ in the presence of different activities of ${ }^{14} \mathrm{C},{ }^{32} \mathrm{P}$, and ${ }^{14} \mathrm{C}$ plus ${ }^{32} \mathrm{P}$. Curves $\mathrm{I}$ and II show theoretical MDAs based on eqs. (1) and (2). Curves III, IV, and $\mathrm{V}$ show MDAs determined experimentally with beta-particle spectrum analysis at the $95 \%$ confidence level with a counting time of 10000 seconds. 
activity as less than $5.5 \mathrm{pCi}$ : the MDA of ${ }^{3} \mathrm{H}$ in the absence of other radionuclides. Fig. 5 shows that with $10000 \mathrm{pCi}$ of ${ }^{14} \mathrm{C}$, the MDA of ${ }^{3} \mathrm{H}$ is approximately $90 \mathrm{pCi}$. Therefore, the sample should be reported to contain less than $90 \mathrm{pCi}$ of ${ }^{3} \mathrm{H}$.

Curve $\mathrm{V}$ in fig. 5 shows the effect of equal activities of ${ }^{14} \mathrm{C}$ and ${ }^{32} \mathrm{P}$ on the MDA of ${ }^{3} \mathrm{H}$. For example, a sample found to contain $1000 \mathrm{pCi}$ each of ${ }^{14} \mathrm{C}$ and ${ }^{32} \mathrm{P}$ would result in an MDA for ${ }^{3} \mathrm{H}$ of about $31 \mathrm{pCi}$. This MDA for ${ }^{3} \mathrm{H}$ could be estimated from curves III and IV by adding the MDA of ${ }^{3} \mathrm{H}$ in the presence of $1000 \mathrm{pCi}$ of ${ }^{14} \mathrm{C}(22 \mathrm{pCi})$ to the MDA of ${ }^{3} \mathrm{H}$ in the presence of $1000 \mathrm{pCi}$ of ${ }^{32} \mathrm{P}(9 \mathrm{pCi})$. This procedure of estimating the MDA of ${ }^{3} \mathrm{H}$ is not limited to samples that contain equal activities of ${ }^{14} \mathrm{C}$ and ${ }^{32} \mathrm{P}$. For example, if a sample were found to contain $5000 \mathrm{pCi}$ of ${ }^{14} \mathrm{C}, 50000 \mathrm{pCi}$ of ${ }^{32} \mathrm{P}$, and no detectable ${ }^{3} \mathrm{H}$, the MDA of ${ }^{3} \mathrm{H}$ would be approximately $110 \mathrm{pCi}$, from curves III and IV of fig. 5.

\section{References}

1) W. L. Oller and P. Plato, Intern J. Appl. Radiation Isotopes 23 (1972) 481.

2) B. Kahn et al., Radiological surveillance studies at a pressurized water nuclear power reactor, U.S. Environmental Protection Agency Publication no. RD 71-1 (National Environmental Research Center, Cincinnati, 1971).

3) W. L. Oller, Beta spectrum analysis: a new method to analyze mixtures of beta-emitting radionuclides by liquid scintillation techniques, Ph. D. Dissertation (Department of Environmental and Industrial Health, The University of Michigan, Ann Arbor, 1973).

4) G. D. Chase and J. L. Rabinowitz, Principles of radioisotope methodology (Burgess Publishing Co., Minneapolis, 1968). 